\title{
The impact of publicly funded rotavirus immunization programs on Canadian children
}

\author{
Pia K Muchaal ${ }^{1 \star}$, Matt Hurst ${ }^{1}$, Shalini Desai ${ }^{2}$
}

\begin{abstract}
Background: In 2008, the National Advisory Committee on Immunization recommended routine rotavirus immunizations in healthy Canadian infants. Over the following seven years, eight provinces and two territories introduced the rotavirus vaccine into their publicly funded immunization programs.
\end{abstract}

Objective: Assess the burden of rotavirus infections before and after implementation of publicly funded immunization programs.

Methods: We analyzed laboratory-confirmed community cases of rotavirus reported to the National Enteric Surveillance Program and hospitalizations of children younger than three years old from 2007 to 2017 with rotavirus diagnosis-specific ICD-10 codes. Rates of illness were calculated for each province for the two years prior to and after implementation of public funding of the vaccine. The year of implementation was not included to accommodate the uptake period of the vaccine. Age-specific rates were assessed in jurisdictions where five years of data were available the year after the vaccine was publicly funded. The pre-post and difference-in-difference (DID) methodologies were applied to hospital discharge data to evaluate changes between the funding and non-funding jurisdictions.

Results: Community cases of laboratory-confirmed rotavirus infection reported to the National Enteric Surveillance Program declined by 54\% between 2010 and 2017. Rates of hospital discharges decreased significantly among children in six provinces after the adoption of the rotavirus vaccine. Hospital discharge rates in Alberta, Manitoba, Ontario and Prince Edward Island dropped between 53\% and 71\%, and by $75 \%$ for British Columbia and Saskatchewan.

Conclusion: Public funding of the rotavirus vaccine appeared to lead to significant reductions in laboratory-confirmed rotavirus cases reported to the National Enteric Surveillance Program and in the rates of rotavirus gastroenteritis-related hospital discharges.
This work is licensed under a Creative Commons Attribution 4.0 International License.

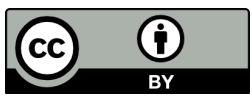

Affiliations

${ }^{1}$ Centre for Foodborne, Environmental and Zoonotic Infectious Diseases, Public Health Agency of Canada, Guelph, ON

${ }^{2}$ Centre for Immunization and Respiratory Infectious Diseases, Public Health Agency of Canada, Ottawa, ON

\section{*Correspondence:}

pia.muchaal@canada.ca

Suggested citation: Muchaal PK, Hurst M, Desai S. The impact of publicly funded rotavirus immunization programs on Canadian children. Can Commun Dis Rep 2021;47(2):97-104.

https://doi.org/10.14745/ccdr.v47i02a02

Keywords: rotavirus, evaluation, vaccination, intervention, burden

\section{Introduction}

Rotavirus is a common, infectious disease transmitted from person to person via the fecal-oral route. In the pre-vaccine era, most children experienced an infection by the time they had reached five years old. Based on limited available data, Thomas et al. estimated that between 2000 and 2010 an average of 850,233 cases of community rotavirus occurred each year in Canada (1).

Clinical presentations vary widely, from asymptomatic infection to severe disease that can lead to severe dehydration and death.
Immunocompromised children are at an increased risk of severe, prolonged and even fatal rotavirus infections (2). In most healthy Canadian children, the illness is self-limiting and rarely results in long-term sequelae or death.

Health Canada has approved two vaccines for use: RotaTeq (Merck Canada Inc.), a three-dose, live, oral pentavalent bovine human rotavirus reassortant, in 2006 (3); and Rotarix (GlaxoSmithKline Inc.), a 2-dose live-attenuated monovalent vaccine derived from a single human strain in 2007 (4). 
The National Advisory Committee on Immunization (NACl) recommended the use in healthy infants of RotaTeq (RV5) in 2008 and of Rotarix in 2010 (5).

Public funding of vaccines is under the purview of the provinces and territories in Canada, and immunization schedules can differ between jurisdictions. By the end of the study period covered in this evaluation (2010-2017), eight provinces and two territories had included rotavirus vaccination in their routine infant immunization schedule. Of these ten jurisdictions, seven are considered in this study (Figure 1). Introductions were temporally staggered across the country between December 2010 and December 2015. By August 2018, nine provinces and three territories had included rotavirus vaccination in their schedules.

\section{Objectives}

Our aim was to study the impact of publicly funded rotavirus vaccination programs by conducting a national analysis of the burden of rotavirus infections in Canada before and after implementation of publicly funded vaccination programs and to compare jurisdictions that adopted the vaccine into their respective routine immunization schedules with those that had not funded the vaccine.

\section{Methods}

\section{Data sources}

The National Enteric Surveillance Program (NESP) tracks the number of laboratory-confirmed cases of community-acquired rotavirus infections reported weekly by all provincial public health laboratories except those in Québec. However, rotavirus is not a nationally reportable disease in Canada, and laboratory testing and reporting vary by jurisdiction. Only a fraction of cases are reported, which leads to underestimating the magnitude of illness. Furthermore, demographic information is not available for these cases. Despite these limitations, the NESP dataset serves as a proxy for trends in community infection.

We obtained weekly counts of rotavirus cases reported to the NESP between 2007 and 2017 from the NESP database. A review of the dataset revealed a paucity of reporting in 2007 to 2009. Therefore, only data from 2010 onwards were submitted for analysis.

Using the Canadian Institute for Health Information (CIHI) Discharge Administration Database (DAD), we assessed hospital discharges between January 1, 2007, and December 31, 2017. CIHI-DAD captures administrative, clinical and demographic information on all hospital discharges from acute care hospitals in all Canadian provinces and territories with the exception of Québec. Clinical diagnoses are classified according to the International Statistical Classification of Diseases and Related Health Problems tenth revision (ICD-10) coding standards. We assessed individual-level records of hospitalization discharges among children younger than three years old with admission dates in CIHI-DAD between January 2007 and December 2017. We defined the primary outcome measure as an individual with either:

- The most responsible diagnosis code of acute rotavirus enteritis (A080.0)

- At least one of the separately recorded diagnoses, of which there are from 2 to 16 , has a code of acute rotavirus enteritis (A080.0)

Nova Scotia publicly funded the rotavirus vaccine in 2019. Although the implementation date is outside of the timeframe considered in this study, one of the province's health authorities participated in a vaccine program in December 2010 with the aim of comparing the efficacy of two delivery systems (6). Therefore, for the purpose of this evaluation, Nova Scotia is assessed as a jurisdiction that also had a vaccine program.

Figure 1: Timeline of adoption of publicly funded rotavirus immunization programs by provinces, 2008-2015

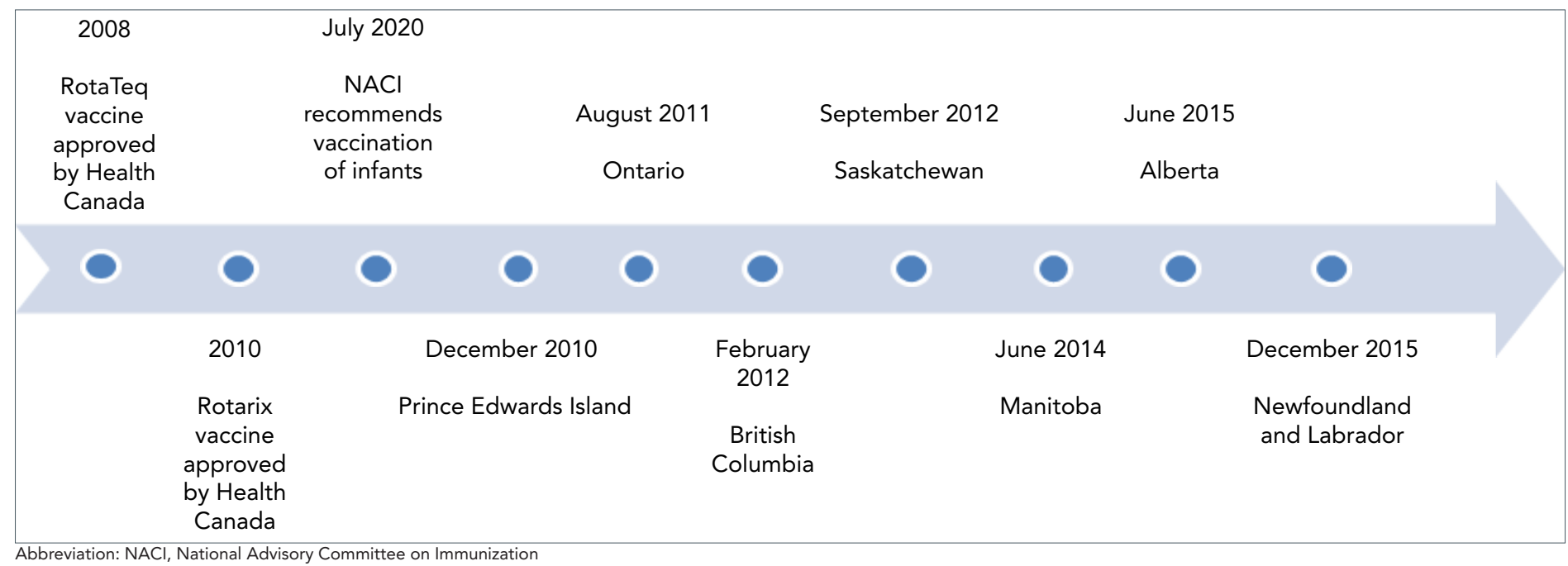


The Northwest Territories, Yukon and Nunavut were excluded from the analysis due to a lack of provincial/territorial reporting and/or a paucity of data from these jurisdictions. In total, these jurisdictions and Québec account for about 23\% of the Canadian population.

We defined the pre and post-funding periods as the two years prior to and the two years after the year the vaccine was adopted into the immunization schedule. The year the vaccine was introduced was excluded from rate calculations to accommodate the vaccine uptake period.

\section{Statistical analysis}

National Enteric Surveillance Program data - community rotavirus infections

We summarized national counts of rotavirus laboratory cases reported to NESP by the participating provinces weekly and annually to reflect general reporting trends of community cases. Rotavirus season onset was identified as the first two consecutive weeks when the number of weekly cases was $15 \%$ over the annual median value or higher. Similarly, end of season was defined as the last two consecutive weeks where the number of cases was $15 \%$, or less, of the median value. The week with the highest number of reported cases is referred to as the season peak.

Canadian Institute for Health Information-Discharge Administration Database data - hospitalizations Children younger than three years old were grouped into one of the following age categories: younger than 12 months; 12 to 23 months; and 24 to 35 months. Statistics Canada population estimates were used to calculate age-specific annual rates of rotavirus gastroenteritis (RVGE) hospital discharges and for the reference periods (7). Rates and 95\% confidence intervals were calculated to estimate the difference between the pre and post-vaccine inclusion periods using the statistical package SAS version 9.3 (SAS Institute Inc., Cary, North Carolina, United States). Statistical significance was defined as $p<0.05$ from a two-sided Wald test.

\section{Difference-in-difference approach}

We used the difference-in-difference (DID) approach, a technique applied to evaluating changes in healthcare policy (8), to assess the impact of vaccinations on RVGE independently of hospitalizations. The key aspect of DID analysis is that, in addition to performing a simple comparison of rates from before and after the intervention (i.e. public funding of the vaccine) to see if rates have changed, there is also an adjustment for the hypothetical situation where there was no intervention and some other event may have been responsible for the observed change. For instance, a mild season of rotavirus after implementation might make the efficacy of the vaccine appear larger than it actually is. The DID approach corrects for this.

\section{Results}

\section{Community rotavirus}

A total of 5,474 cases were reported to NESP between 2010 and 2017 , with $76 \%$ of these cases reported over the first four years (2010-2013). Sustained and significant decreases $(p<0.05)$ in the annual cases reported nationally to NESP occurred in subsequent years (2014-2017). At the peak of the 2011 rotavirus season, 137 cases were reported (annual median=14 per week) compared to a peak of 15 cases in 2017 (median=6) (Table 1; Figure 2). Over the seven-year period, the duration of the rotavirus season varied between 25 and 31 weeks. Between 2010 and $2015,90 \%$ to $94 \%$ of annual cases were reported within the rotavirus season. Over 2016 to 2017, approximately 4\% fewer cases were reported during the season, while more sporadic cases were reported at other times of the year.

Table 1: Cases of rotavirus reported annually to National Enteric Surveillance Program, 2010-2017

\section{Statistics} \begin{tabular}{|l|l|l|l|l|l|l|l|}
2010 & 2011 & 2012 & 2013 & 2014 & 2015 & 2016 & 2017 \\
\hline
\end{tabular}

\begin{tabular}{|l|r|r|r|r|r|r|r|r|}
\hline $\begin{array}{l}\text { Total no. of cases } \\
\text { reported }\end{array}$ & 828 & 1,573 & 803 & 773 & 425 & 433 & 258 & 381 \\
\hline $\begin{array}{l}\text { Percentage of 10- } \\
\text { year total (\%) }\end{array}$ & 15.1 & 28.7 & 14.7 & 14.1 & 7.8 & 7.9 & 4.7 & 7.0 \\
\hline $\begin{array}{l}\text { Median no. of } \\
\text { cases }\end{array}$ & 8 & 14 & 9 & 6 & 4 & 5 & 3 & 6 \\
\hline Timing of season & 1 & 1 & 4 & 3 & 2 & 2 & 4 & 5 \\
\hline $\begin{array}{l}\text { Onset (NESP } \\
\text { week) }\end{array}$ & 15 & 17 & 19 & 16 & 11 & 15 & 22 & 17 \\
\hline \begin{tabular}{l} 
Peak \\
\hline End
\end{tabular} & 29 & 28 & 31 & 28 & 33 & 28 & 32 & 31 \\
\hline $\begin{array}{l}\text { Duration (weeks) } \\
\text { No. of cases at } \\
\text { peak }\end{array}$ & 65 & 137 & 56 & 70 & 27 & 35 & 18 & 27 \\
\hline $\begin{array}{l}\text { Percentage of } \\
\text { annual cases } \\
\text { reported in season } \\
\text { (\%) }\end{array}$ & 91.4 & 94.4 & 90.5 & 91.6 & 92.2 & 90.8 & 86.0 & 86.3 \\
\hline \begin{tabular}{l} 
Abbreviation: NESP, National Enteric Surveillance Program \\
\hline
\end{tabular} & & 25 & 31 & 26 & 28 & 26 \\
\hline
\end{tabular}

\section{Canadian Institute for Health Information- Discharge Administration Database data - hospital discharges}

In the study period (2007-2017), infants and children younger than three years old comprised $70 \%(N=7,668)$ of all hospital RVGE discharges. In this group of children, RVGE was the "most responsible diagnosis" for $82 \%(n=5,379)$ of hospital discharges. Boys comprised $56 \%$ of discharged cases under three years old.

Overall, Canadian rates of rotavirus-related hospital discharges declined after provinces commenced funding rotavirus immunizations subsequent to the $2010 \mathrm{NACl}$ recommendations (Table 2). A national comparison of pre and post-vaccine funding periods showed a reduction of 48.2 cases per $100,000(95 \% \mathrm{Cl}$, $43.9,52.6)$ during the observation period. 
Figure 2: Weekly cases of laboratory-confirmed reported to National Enteric Surveillance Program, 2010-2017

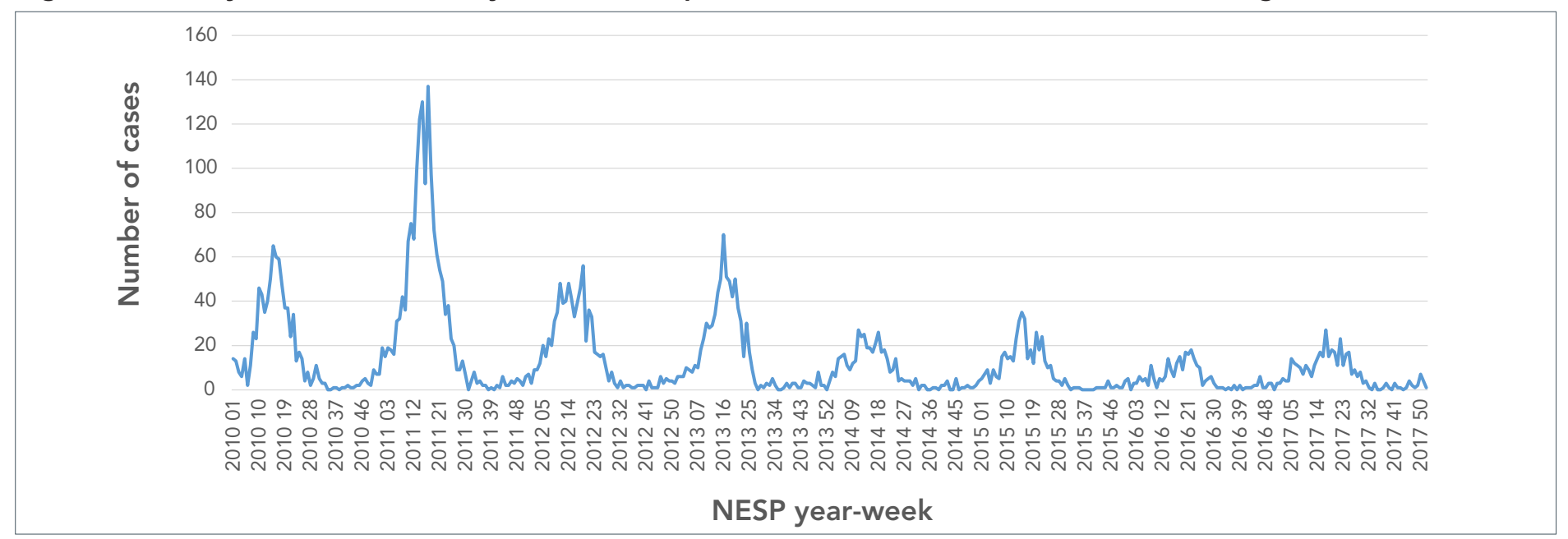

Abbreviation: NESP, National Enteric Surveillance Program

Table 2: Annual rates per 100,000 and $95 \%$ confidence intervals of rotavirus acute gastroenteritis hospital discharges among children two years or younger

\begin{tabular}{|c|c|c|c|c|c|c|c|c|c|c|}
\hline \multirow{4}{*}{ Province } & \multicolumn{6}{|c|}{ Hospital discharges } & \multicolumn{4}{|c|}{$\begin{array}{c}\text { Pre-vaccine vs post-vaccine rate } \\
\text { difference }^{\text {a }}\end{array}$} \\
\hline & \multicolumn{3}{|c|}{ Pre-vaccine funding } & \multicolumn{3}{|c|}{ Post-vaccine funding } & \multirow{2}{*}{ Rate } & \multirow{2}{*}{$\mathrm{LCL}$} & \multirow{2}{*}{ UCL } & \multirow{2}{*}{$\%$ change } \\
\hline & Rate & LCL & UCL & Rate & LCL & UCL & & & & \\
\hline & \multicolumn{3}{|c|}{ 2009-2010 } & \multicolumn{3}{|c|}{ 2012-2013 } & \multicolumn{4}{|c|}{$2009-2010$ vs $2012-2013$} \\
\hline Prince Edward Island & 241.7 & 138.3 & 345.0 & 70.8 & 14.1 & 127.5 & $-170.8^{a}$ & -288.7 & -53.0 & 70.7 \\
\hline Ontario & 96.9 & 90.3 & 103.6 & 45.3 & 40.8 & 49.9 & $-51.6^{a}$ & -43.5 & -59.6 & 53.2 \\
\hline \multirow[t]{2}{*}{ New Brunswick } & 130.7 & 97.1 & 164.4 & 166.6 & 128.1 & 205.1 & $35.8^{a}$ & 78.0 & 188.8 & 10.6 \\
\hline & \multicolumn{3}{|c|}{ 2010-2011 } & \multicolumn{3}{|c|}{ 2013-2014 } & \multicolumn{4}{|c|}{ 2010-2011 vs 2013-2014 } \\
\hline British Columbia & 31.7 & 24.9 & 38.4 & 7.9 & 4.5 & 11.3 & $-23.8^{\mathrm{a}}$ & -31.4 & -16.3 & 75.1 \\
\hline Saskatchewan & 288.7 & 252.5 & 324.8 & 71.2 & 53.6 & 88.7 & $-217.5^{a}$ & -257.7 & -177.3 & 75.3 \\
\hline \multirow[t]{2}{*}{ New Brunswick } & 169.6 & 131.2 & 208.0 & 169.8 & 130.6 & 209.7 & 0.23 & -46.9 & 47.4 & NS \\
\hline & \multicolumn{3}{|c|}{ 2012-2013 } & \multicolumn{3}{|c|}{ 2015-2016 } & \multicolumn{4}{|c|}{$2012-2013$ vs $2015-2016$} \\
\hline Manitoba & 14.6 & 6.9 & 22.2 & 4.9 & 0.6 & 9.3 & -9.6 & -18.4 & -0.8 & NS \\
\hline \multirow[t]{2}{*}{ New Brunswick } & 155.1 & 117.9 & 192.1 & 118.8 & 85.6 & 152.1 & -36.2 & -80.9 & 8.5 & NS \\
\hline & \multicolumn{3}{|c|}{ 2013-2014 } & \multicolumn{3}{|c|}{ 2016-2017 } & \multicolumn{4}{|c|}{$2013-2014$ vs $2016-2017$} \\
\hline Alberta & 59.0 & 50.1 & 67.4 & 19.5 & 14.8 & 24.3 & $-39.0^{a}$ & -96.6 & -29.4 & 67.0 \\
\hline \multirow[t]{2}{*}{ New Brunswick } & 169.8 & 130.6 & 209.1 & 121.8 & 88.0 & 155.5 & $-48.1^{a}$ & -95.1 & -1.1 & 28.3 \\
\hline & \multicolumn{3}{|c|}{ 2014-2015 } & \multicolumn{3}{|c|}{ 2016-2017 } & \multicolumn{4}{|c|}{$2014-2015$ vs 2017} \\
\hline $\begin{array}{l}\text { Newfoundland \& } \\
\text { Labrador }\end{array}$ & 14.6 & 0.3 & 28.9 & 14.8 & -5.7 & 35.3 & 0.2 & -65.3 & -16.6 & NS \\
\hline \multirow[t]{2}{*}{ New Brunswick } & 143.7 & 107.0 & 180.4 & 122.3 & 74.4 & 170.3 & -21.3 & -68.3 & 25.5 & NS \\
\hline & \multicolumn{3}{|c|}{ 2009-2010 } & \multicolumn{3}{|c|}{$2012-2013$} & \multicolumn{4}{|c|}{$2009-2010$ vs $2012-2013$} \\
\hline Nova Scotia & 94.3 & 68.4 & 120.2 & 34.1 & 18.3 & 49.8 & $-60.3^{a}$ & -119.5 & -30.2 & 64.0 \\
\hline New Brunswick & 130.7 & 97.1 & 164.4 & 166.6 & 128.1 & 205.1 & $35.8^{\mathrm{a}}$ & 78.0 & 188.8 & 10.6 \\
\hline
\end{tabular}

Abbreviations: $L C L$, lower confidence limit; NS, not significant; $\mathrm{UCL}$, upper confidence limit

Note: The same period was used to assess changes in rates for the non-implementing province, New Brunswick (name bolded) 
Mean rates of RVGE hospital discharges of children declined by between $53 \%$ and $76 \%$ across the provinces after the implementation of publicly funded vaccination programs in six of the seven jurisdictions, Prince Edward Island, Ontario, British Columbia, Saskatchewan, Manitoba and Alberta. RVGE discharge rates also dropped in Nova Scotia. There was a fractional, but not significant, increase in the hospital discharge rates of children in Newfoundland and Labrador (Table 2).

Within five years of the rotavirus vaccine being funded by the earliest adopters-Prince Edward Island, Ontario, British Columbia and Saskatchewan-RVGE discharge rates declined among children under three years of age. In these four provinces, such reductions were most prominent (over 85\%) among infants and one-year-old children (Figure 3 ). There was also a statistically significant decrease in hospital discharge rates of two-year old children in Ontario and Saskatchewan.

Publicly funded immunization programs, as measured through a DID approach, reduced RVGE hospital discharge rates in Prince Edward Island, Ontario and Saskatchewan $(p \leq 0.01)$ (Table 3). The program in Saskatchewan generated a prominent decrease of 201.4 cases per $100,000(95 \% \mathrm{Cl},-258.1,-144.8)$. Among children in Prince Edward Island, discharge rates dropped by 182.4 cases per $100,000(95 \% \mathrm{Cl},-308.6,-56.2)$. In Ontario, a decline of $63.1(95 \% \mathrm{Cl},-108.9,-17.4)$ was noted.

Figure 3: Discharges per 100,000 of rotavirus gastroenteritis hospital discharges in the first five provinces to adopt the vaccine and New Brunswick, children younger than three years, by age group

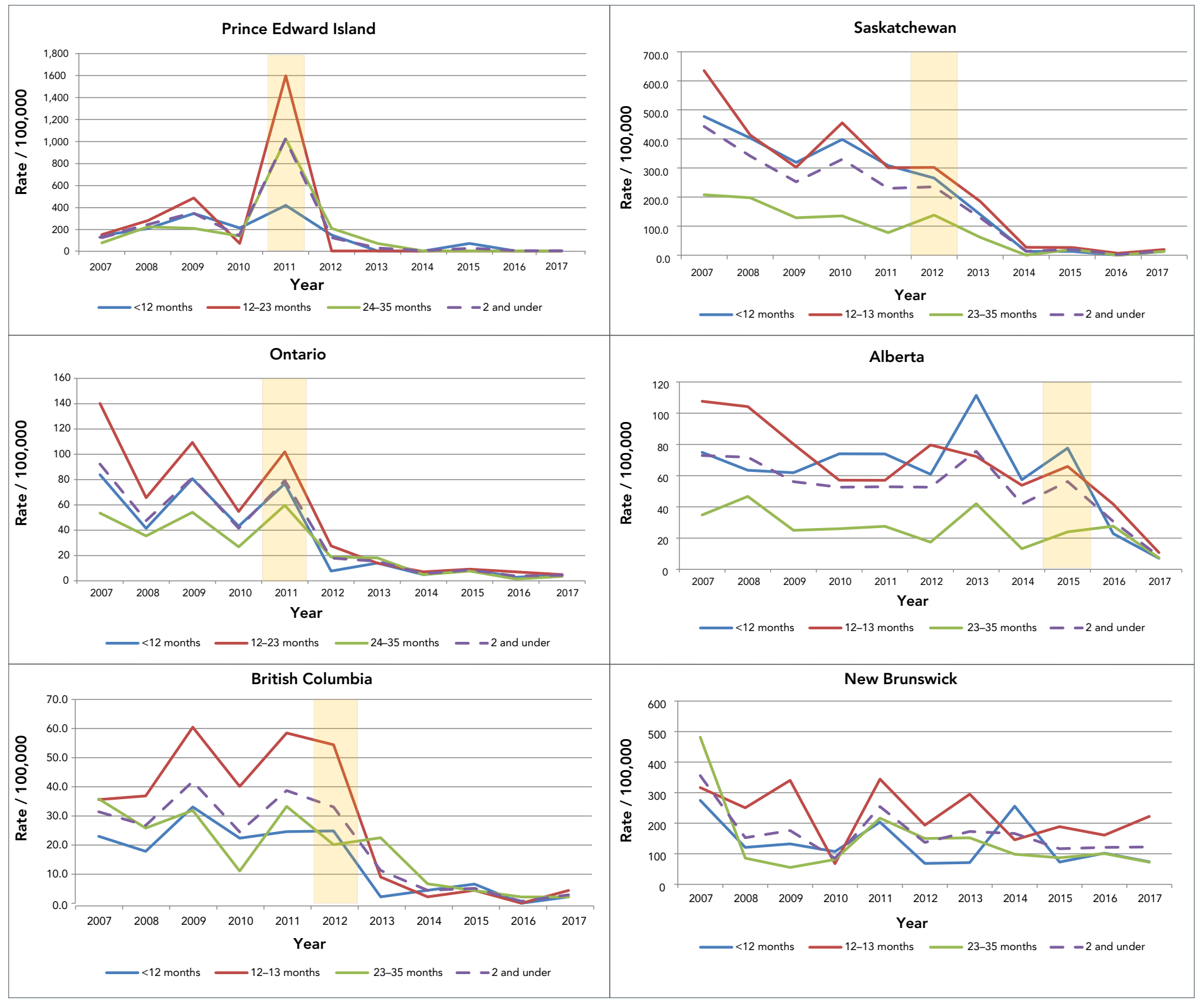


Table 3: Difference-in-difference estimates: impact of publicly funded vaccination programs on the rate of rotavirus gastroenteritis hospital discharges per 100,000 , by province

\begin{tabular}{|c|c|c|c|}
\hline \multirow[b]{2}{*}{ Province } & \multicolumn{3}{|c|}{$\begin{array}{l}\text { Treatment effect }{ }^{\mathrm{a}} \text { between implementing } \\
\text { jurisdiction and control }\end{array}$} \\
\hline & $\begin{array}{l}\text { Change in } \\
\text { rate per } \\
100,000\end{array}$ & $\begin{array}{c}\text { Lower } \\
\text { confidence } \\
\text { limit }\end{array}$ & $\begin{array}{c}\text { Upper } \\
\text { confidence } \\
\text { limit }\end{array}$ \\
\hline $\begin{array}{l}\text { Prince Edward } \\
\text { Island }\end{array}$ & $-182.4^{c}$ & -308.6 & -56.2 \\
\hline Ontario & $-63.1^{c}$ & -108.9 & -17.4 \\
\hline $\begin{array}{l}\text { British } \\
\text { Columbia }\end{array}$ & -24.1 & -79.5 & 31.3 \\
\hline Saskatchewan & $-201.4^{c}$ & -258.1 & -144.8 \\
\hline Manitoba & 3.5 & -42.9 & 50.0 \\
\hline Alberta & -3.2 & -51.9 & 45.5 \\
\hline $\begin{array}{l}\text { Newfoundland } \\
\text { and Labrador }\end{array}$ & 16.9 & -46.1 & 79.8 \\
\hline Nova Scotia & 9.1 & -22.4 & 40.6 \\
\hline
\end{tabular}

\section{Discussion}

The two lines of evidence considered in this study identified decreasing rates of hospital discharges and community cases attributed to rotavirus infections in the regions where the rotavirus vaccine was publicly funded. Temporally, public funding appeared to lead to significant reductions in i) reports of laboratory-confirmed rotavirus cases reported by the provinces to NESP; and ii) RVGE-related hospital discharges.

The rates of RVGE reported to NESP dropped over $50 \%$ within the four years after provinces began implementing publicly funded immunization programs. Pre-post estimates of vaccine impact on RVGE hospital discharge rates were significantly lower for infants and one-year-old children in the provinces that funded the vaccine between December 2010 and September 2012. The dramatic rate reductions in young children is not unexpected, as historically these age groups have the highest rates of illness and so would benefit most from the direct effect of the vaccine with good coverage in the population. The Childhood National Immunization Coverage Survey (9) reported coverage of rotavirus vaccine by the early adopting provinces to be $75.4 \%$. Rates of vaccination coverage for rotavirus at the national level were not available prior to 2013 .

Among the early-implementing provinces, the proportion of children under two years of age who had received the rotavirus vaccine was similar: British Columbia reported in 2015 that $75 \%$ of children aged younger than two years had received the two recommended doses of rotavirus (10). In the same year, $80 \%$ of
Saskatchewan children under eight months had received the two recommended doses of rotavirus (11). Coverage assessments in Ontario showed rotavirus vaccine uptake had increased to $83 \%$ by 2014 (12). In Prince Edward Island, where infant immunizations are delivered exclusively by public health nurses, coverage estimates are greater than $90 \%(5)$.

Though not as large, there was a distinct decline in RVGE-associated events in children in Alberta. These data may indicate lower coverage rates compared to the early adopters as the programs were underway only in the later stages of the study period. DID approach estimates for British Columbia and Alberta were not statistically significant, likely because the effects were much smaller and the effect was thus harder to detect. The DID approach found no significant reductions in RVGE hospital discharges for Nova Scotia. Our results parallel the findings from the investigation by Sanford et al. (6) that aimed to assess the relative effectiveness of public health nurses and physician offices as immunization delivery systems. The authors noted that there were no reductions in RVGE hospitalizations in study areas with low vaccine coverage. The vaccine coverage was less than $40 \%$ in the Nova Scotia setting.

Hospital RVGE discharge rates among children younger than two years old declined by more than $80 \%$ between the pre and post periods. By contrast, RVGE rates in New Brunswick, the comparison group, remained unchanged. This supports the claim that the public funding of the vaccine in Canada has been the cause of declining rotavirus infections and not a temporally aligned third factor, such as a milder season of rotavirus.

To date, three Canadian provinces, Ontario, Prince Edward Island and Québec have completed large cohort or population-based vaccination-impact studies for their respective jurisdictions. Each of these studies demonstrated large reductions in RVGE following the implementation of publicly funded programs. The program in Ontario translated to a reduction of up to $79 \%$ for RVGE hospitalizations in youth and children younger than 20 years old $(12,13)$. A study in Québec identified an $80.1 \%$ reduction in positive tests of RVGE at the Montréal Children's Hospital in 2012 to 2013, a year after the vaccine was introduced, compared to 2006 to 2009 (14). In Prince Edward Island, a universal infant rotavirus vaccine program delivered by public health nurses resulted in the elimination of RVGE hospitalizations among children younger than 24 months old by the second year of the program (5).

The declines noted in the national study presented here and the individual provincial assessments are consistent with findings in multiple high-income countries where RVGE-related hospitalizations fell due to similar vaccination programs. Investigations on the impact of rotavirus vaccinations campaigns conducted in high-income countries reported modest to dramatic reductions in rotavirus hospital admissions, depending on the population assessed $(15,16)$. 
Immunization can give rise to changes in disease transmission, reducing illness directly in the vaccinated population and indirectly in unvaccinated individuals (17). Indirect immunity may be generated by community immunity (18). The data available for this study are insufficient to ascertain whether unvaccinated children remained free of illness. However, under a publicly funded immunization program, it is assumed that the majority of the target population will be administered the vaccine.

\section{Limitations}

There are several limitations to our study. First, we did not know the vaccine status of cases. In addition, rotavirus infections are not nationally reportable, and so there is no single monitoring system to capture all occurrences of rotavirus in Canadian communities. We therefore leveraged one national surveillance program and hospital discharge data as surrogates. However, doing so was not without challenges. The NESP data are devoid of information on age and sex, and reported cases may be older than the age group considered in this study. Limited diagnostic testing of symptomatic cases results in an under-representation of cases reported to all databases.

Furthermore, clinical presentation of rotavirus disease can be indistinguishable from other forms of acute diarrhea and most cases are treated symptomatically. The symptomatic treatment of acute gastroenteritis cases and the nature of reporting RVGE results in relatively low apparent annual rates of infection. This creates a problem in interpreting the burden of disease, as these rates of infection are, to a large degree, negatively biased. Nonetheless, we were primarily interested in trends, that is, how these rates may have fallen as a result of vaccination interventions. To do this, we assume that any reporting biases that existed in each system remain the same from year to year.

Also of note, hospital data from Québec are not available through the CIHI-DAD system, and hospital discharge data from Northwest Territories, Yukon and Nunavut are scarce. These four jurisdictions, comprising approximately $23 \%$ of the Canadian population, were not included in this study.

Though we observed significant decreases in disease burden after introduction of the vaccine, the reductions may not be due to vaccine alone. Years of low RVGE activity have been reported in the absence of vaccination, as was the case in the Netherlands in 2013-2014 (19). Natural fluctuations in disease incidence could have contributed to the observations presented here. The use of the DID estimator moderates this limitation.

\section{Conclusion}

In summary, this is a national evaluation of rotavirus vaccine programs in Canada. Our evaluation uses an innovative approach, the DID methodology, to show that depending on when programs were implemented rates of rotavirus-related infections and hospitalizations decreased. Further investigations using innovative methods will be required to detect further changes over time.

\section{Authors' statement}

PKM - Conceptualization, investigation, data curation, formal analysis, drafting original manuscript

$\mathrm{MH}$ - Methodology, reviewing \& editing manuscript

SD - Conceptualization, reviewing \& editing manuscript

\section{Competing interests}

None.

\section{Acknowledgements}

This work was supported by the Public Health Agency of Canada.

\section{Funding}

All efforts related to this project were undertaken as part of the obligations of the Centre for Foodborne, Environmental and Zoonotic Infectious Diseases and the Centre for Immunization and Respiratory Infectious Diseases. No external sources of funds were provided for the completion of this work.

\section{References}

1. Thomas MK, Murray R, Flockhart L, Pintar K, Pollari F, Fazil A, Nesbitt A, Marshall B. Estimates of the burden of foodborne illness in Canada for 30 specified pathogens and unspecified agents, circa 2006. Foodborne Pathog Dis 2013;10(7):639-48. DOI PubMed

2. Salvadori M, Le Saux N. Recommendations for the use of rotavirus vaccines in infants. Paediatr Child Health 2010;15(8):519-28. DOI PubMed

3. Health Canada. Notice of compliance information. Ottawa (ON): Health Canada; (modified 2019-1021; accessed 2020-05-05). https://hpr-rps.hres.ca/ reg-content/summary-basis-decision-detailOne. php?lang=en\&linkID=SBD00130

4. Health Canada. Notice of compliance database search results. Ottawa (ON): Health Canada; (modified 201910-21; accessed 2020-05-05). https://hpr-rps.hres. $\mathrm{ca} /$ reg-content/summary-basis-decision-detailOne. php?lang=en\&linkID=SBD00129

5. An Advisory Committee Statement (ACS) National Advisory Committee on Immunization ( $\mathrm{NACl}$ ). Statement on the recommended use of pentavalent human-bovine reassortant rotavirus vaccine. Can Commun Dis Rep 2008;34(ACS-1):1-33. https://www.canada. $\mathrm{ca} / \mathrm{en} /$ public-health/services/reports-publications/ canada-communicable-disease-report-ccdr/ monthly-issue/2008-34/statement-pentavalen t-human-bovine-reassortant-rotavirus-vaccine.html 
6. Sanford C, Langley JM, Halperin SA, Zelman M and MURVP Maritime Universal Rotavirus Vaccination Program. A universal infant rotavirus vaccine program in two delivery models: effectiveness and adverse events following immunization. Hum Vaccin Immunother 2015;11(4):870-4. DOI PubMed

7. Statistics Canada. Table 17-10-0005-01 Population estimates on July $1^{\text {st }}$, by age and sex. Ottawa (ON): Statistics Canada; 2017 (accessed 2020-03-15). DOI

8. Dimick JB, Ryan AM. Methods for evaluating changes in health care policy: the difference-in-differences approach. JAMA 2014;312(22):2401-2. DOI PubMed

9. Statistics Canada. Childhood National Immunization Coverage Survey, 2015. The Daily, June 28, 2017. https:// www.statcan.gc.ca/daily-quotidien/170628/dq170628a-eng. pdf

10. BC Centre for Disease Control. Immunization uptake in children by the second birthday, 2007-2017. Vancouver (BC): BCCDC; (updated 2018-01-15; accessed 2018-04-16). http:// www.bccdc.ca/Health-Professionals-Site/Documents/2_Year_ Old_Coverage_2005-2015_Birth_Cohorts\%20(2).pdf

11. CANVAX. Vaccine preventable disease monitoring report: rotavirus, 2015 and 2016. Saskatchewan (SK): Saskatchewan Ministry of Health Population Health Branch; 2017 July (accessed 2018-04-16). https://www.saskatchewan.ca/search \#q=rotavirus\&sort=relevancy

12. Wilson SE, Rosella LC, Wang J, Le Saux N, Crowcroft NS, Harris T, Bolotin S, Deeks SL. Population-level impact of Ontario's infant rotavirus immunization program: evidence of direct and indirect effects. PLoS One 2016;11(5):e0154340. DOI PubMed

13. Wilson SE, Chung H, Schwartz KL, Guttmann A, Deeks SL, Kwong JC, Crowcroft NS, Wing L, Tu K. Rotavirus vaccine coverage and factors associated with uptake using linked data: Ontario, Canada. PLoS One 2018;13(2):e0192809. DOI PubMed
14. Comeau JL, Gagneur A, Quach C. Impact of a publicly funded monovalent rotavirus vaccination program in the Province of Quebec (Canada). Vaccine 2016;34(7):893-8. DOI PubMed

15. Panozzo CA, Becker-Dreps S, Pate V, Weber DJ, Jonsson Funk M, Stürmer T, Brookhart MA. Direct, indirect, total, and overall effectiveness of the rotavirus vaccines for the prevention of gastroenteritis hospitalizations in privately insured US children, 2007-2010. Am J Epidemiol 2014;179(7):895-909. DOI PubMed

16. Patel MM, Glass R, Desai R, Tate JE, Parashar UD. Fulfilling the promise of rotavirus vaccines: how far have we come since licensure? Lancet Infect Dis 2012;12(7):561-70. DOI PubMed

17. Zepp F, Heininger U, Mertsola J, Bernatowska E, Guiso N, Roord J, Tozzi AE, Van Damme P. Rationale for pertussis booster vaccination throughout life in Europe. Lancet Infect Dis 2011;11(7):557-70. DOl PubMed

18. Tsai CJ, Griffin MR, Nuorti JP, Grijalva CG. Changing epidemiology of pneumococcal meningitis after the introduction of pneumococcal conjugate vaccine in the United States. Clin Infect Dis 2008;46(11):1664-72. DOI PubMed

19. Hahné S, Hooiveld $M$, Vennema $H$, van Ginkel $A$, de Melker $\mathrm{H}$, Wallinga J, van Pelt W, Bruijning-Verhagen P. Exceptionally low rotavirus incidence in the Netherlands in $2013 / 14$ in the absence of rotavirus vaccination. Euro Surveill 2014;19(43):20945.

DOI PubMed 